\title{
Methods of Calculation of Expected Credit Losses Under Requirements of IFRS 9
}

\author{
Alfiya Vasilyeva \\ PhD Student \\ $\underline{\text { ORCID }}$ \\ E-mail: alfiavaf@mail.ru
}

National Research University Higher School of Economics, Moscow, Russia

\section{Elvina Frolova}

PhD Student

ORCID

E-mail: elvinafa@gmail.com

MGIMO University, Moscow, Russia

Journal of Corporate Finance Research, Vol. 13, No. 4, pp. 74-86 (2019)

DOI: https://doi.org/10.17323/j.jcfr.2073-0438.13.4.2019.74-86

Received 15 July 2019 | Peer-reviewed 12 September 2019 | Accepted 3 December 2019 


\section{Methods of Calculation of Expected Credit Losses Under Requirements of IFRS 9}

\section{Abstract}

The most important area of work for financial market regulators including International Accounting Standards Board is to clarify the metrics of credit assessment.

This problem became particularly relevant after the financial crisis of 2008, when the insolvency of approaches to the assessment of credit risks adopted under the then international financial reporting standard IFRS (IAS) 39 became apparent, since credit losses on financial instruments were taken into account by the "loss model", and therefore, the asset was recognized as financially impaired due to the fact of credit quality deterioration and significant time lag. From 1 January 2018 of a new international financial reporting standard IFRS9

IFRS 9 is based on a different approach - the principle of "expected credit losses" (ECL).

The transition to IFRS 9 is intended to strengthen the banking system by increasing reserves, the banking system's stability can be increased also. The new business model radically changes the approach to the formation of reserves, including by taking into account the impact of macroeconomic indicators on their value. According to various estimates, the scale of increase in reserves ranges from $30 \%$ to $50 \%$.

The purpose of this article is to systematize the methodological principles and approaches that underlie the requirements of IFRS 9 (basic and simplified and POCI approaches), as well as a comparison of the main methods for assessing the probability of default and expected credit losses (Weibul distribution, migration matrix, generator matrix) In the framework of this article, the authors formulated criteria for the transfer of assets between the stages of credit risk (stage), and also formulated the principles for calculating expected credit risks for each stage, taking into account macroeconomic factors. This article is of practical value, as it can be the basis for the development of methods for calculating the expected credit risks of corporate clients of commercial banks, and can also be used to improve credit risk management models.

Keywords: IFRS 9, expected credit losses, credit risk assessment stages

JEL classification: B40, G21, F65 


\section{Introduction}

In the previous standard (IFRS 39) the model of actually incurred losses should have been used [1]. It resulted in deferred recognition of credit losses because only the events that have occurred and current conditions influence the credit risk evaluation and the effect of possible future credit losses was not taken into consideration when calculations were made even if they were already expected at the moment [2].

Standard IFRS 9 is intended to solve this problem and is based on the model of expected credit losses [3].

Another change in approaches to credit risk evaluation may be considered recording of forward-looking information on the basis of macroeconomic forecasts (change of inflation, currency rate etc.).

Thus, implementation of this standard is intended to improve the existing approaches to credit risks management. IFRS 9 contemplates applying of ECL uniform model by using three approaches:

1) general approach used for the majority of credits and debt securities;

2) simplified approach applied to accounts receivable;

3) the approach which will be applied to financial assets which have been credit impaired at initial recognition.

The Fundamental Principles of Creation of Reserves for a Business Portfolio

In order to record financial instruments on the reports under IFRS the Bank creates reserves in the amount necessary to cover the expected credit losses in accordance with IFRS 9. As per IFRS 9 there are three approaches to ECL assessment:

The main approach, based on three credit risk stages:

- First stage - financial instruments which showed no significant increase of credit risk since the first recognition; reserves amount to 12-months' ECL (or for the whole life if it is less than 12 months); the interest return is calculated on the basis of the balance sheet value.

- $\quad$ Second stage - financial instruments which show a significant increase of credit risk but are not impaired ones; reserves amount to ECL for the whole life of an asset; the interest return is calculated on the basis of the balance sheet value.

- Third stage - impaired financial instruments; reserves amount to ECL for the whole life of an asset; the interest return is calculated on the basis of the amortized cost.

Simplified approach - the reserve is assessed as amounting to ECL for the whole life of an asset or in accordance with the principal approach.

Approach for POCI - at first recognition the reserve is not created, an asset is carried at adjusted value after deduction of the impairment effect; the interest return is calculated on the basis of the adjusted effective rate of the amortized cost; subsequent assessment of the reserve amounts to the change of ECL for the whole life.

The date of first recognition usually is understood as the date of signing the contract.

\section{The main approach: credit quality deterioration model}

The main approach to calculation consists in a sequential estimate of the credit risk components and further calculation of ECL value. There are four main stages of calculation:

- assignment of financial instruments to a certain Impairment Stage;

- defining the value of the credit risk components PD, LGD, EAD;

- defining ECL value for each Impairment Stage;

- calculation of the reserve amount which corresponds to the aggregative value of ECL for all Impairment Stages:

Reserve $=\mathrm{ECL}_{\text {Stage } 1}+\mathrm{ECL}_{\text {Stage2 }}+\mathrm{ECL}_{\text {Stage3 }}$,

where

$\mathrm{ECL}_{\text {Stage }}$ - reserve of financial instruments assigned to Stage 1,

$\mathrm{ECL}_{\text {Stage2 }}$ - reserve of financial instruments assigned to Stage 2,

$\mathrm{ECL}_{\text {Stage3 }}$ - reserve of financial instruments assigned to Stage 3.

According to requirements of IFRS 9 it is necessary to have assessment of ECL for 12 months for financial instruments with no significant increase of credit risk since the first recognition and assessment of ECL for the whole life for financial instruments with a significant increase of credit risk since the first recognition as well as for impaired financial instruments.

\section{Simplified approach}

The simplified approach is applied to financial instruments classified as accounts receivable (see the definition in Appendix 1).

The Bank calculates ECL for the whole life of an instrument (including the cases when the life is less than 12 months) for all instruments for which ECL is calculated using the simplified approach except for the cases when the amount of credit requirements is significant in comparison to the portfolio of instruments which belong to accounts receivable. The Bank defines the criteria of significance at its own discretion.

A particular approach to the assets which are purchased or originated credit-impaired at first recognition (POCI).

The expected credit losses of POCI assets are always assessed for the period equal to the life period of the financial instrument. 
Table 1. Assigning stages at first recognition

\begin{tabular}{lll} 
Stage & First recognition \\
\hline 1 & In case of absence of impairment indicators \\
\hline 2 & - & POCI
\end{tabular}

On subsequent assessment the Bank pursues the following approach:

Table 2. Assigning stages after the initial assessment [4]

\begin{tabular}{|c|c|c|c|}
\hline $\begin{array}{l}\text { Stage } \\
\text { transfer }\end{array}$ & \multicolumn{3}{|c|}{ to } \\
\hline \multirow{3}{*}{ from } & $\begin{array}{l}\text { Absence of a significant increase of } \\
\text { credit risk }\end{array}$ & $\begin{array}{l}\text { A significant increase of credit } \\
\text { risk }\end{array}$ & Impairment \\
\hline & $\begin{array}{l}\text { Absence of a significant increase of } \\
\text { credit risk } \\
\text { Restoring (except for POCI) }\end{array}$ & $\begin{array}{l}\text { A significant increase of credit } \\
\text { risk persists }\end{array}$ & Impairment \\
\hline & $\begin{array}{l}\text { Restoring (in the absence of criteria of } \\
\text { Stage } 3 \text { and Stage } 2 \text { (except for POCI) }\end{array}$ & $\begin{array}{l}\text { Restoring (in the absence of } \\
\text { criteria of Stage } 3 \text { and presence } \\
\text { of criteria of Stage } 2 \text { (except for } \\
\text { POCI) }\end{array}$ & $\begin{array}{l}\text { Absence of restoring } \\
\text { (criteria of Stage } 3 \text { are } \\
\text { met) } \\
\text { or POCI asset }\end{array}$ \\
\hline
\end{tabular}

POCI assets are not transferred to other stages. See the arrangement of defining the impairment stage in Appendix 3.

Table 3. Criteria of transfer to Stage 2

$\begin{array}{ll}\text { Criteria group } & \begin{array}{l}\text { Criteria used in the Bank } \\ \text { Change of one-year PD (as of the reporting date) / rating (as of the report- } \\ \text { ing date) with respect to a forcast of one-year PD calculated at first recog- } \\ \text { nition (as of the reporting date) / rating predicted at first recognition (as } \\ \text { of the reporting date), by factor of N. Threshold values of N are defined by } \\ \text { the Bank. }\end{array} \\ \text { Number of days of delay in payment } \quad \begin{array}{l}\text { Number of days of current delay in payment under a contract is } 31 \text { and } \\ \text { more, but it does not exceed } 90 \text { days }\end{array}\end{array}$

The asset is transferred back to Stage 1 in case of absence of the abovementioned criteria and/or criteria of Stage 3.

At first recognition a reserve for POCI assets is not created. The expected credit losses for the whole life of a financial instrument are recorded by adjusting the effective interest rate.

The amount of the reserve for POCI assets equals to the amount of changes in the losses expected during the whole life of an asset since the date of its first recognition. The expected life of each asset is defined individually.

\section{Defining the Criteria of Transfer from one Stage to Another One}

Speaking of the transfer criteria a symmetrical stage transfer logic is applied. It means that as of each reporting date the assets may be assigned both a higher credit risk stage (in case of meeting the criteria confirming a significant increase of credit risk or impairment), and a lower credit risk stage, in comparison with the previous reporting date (in case the criteria of assignment to the $2^{\text {nd }}$ and $3^{\text {rd }}$ stage are no longer met due to improvement of the credit quality). There are differences in the general approach and the approach for POCI assets at the first and subsequent assessment. Purchased or originated credit-impaired assets at first recognition are assigned to the $3^{\text {rd }}$ stage and are not transferred to other Stages during the period of recognition.

At first recognition the Bank pursues the following approach:

- if an asset is not a credit-impaired one it is assigned to the first stage;

- if an asset is a credit-impaired one at first recognition (POCI) it is assigned to the third stage;

- at first recognition an asset may not be assigned to the second stage. 


\section{Criteria of transfer to Stage 2}

In order to define an asset with a significant increase of credit risk (quantitative criterion) the Bank compares the default risk as of the reporting date to a corresponding assessment at first recognition (IFRS 9.B5.5.9). The criteria of a significant risk increase are stated in the table below.

\section{Criteria of transfer to Stage 3 (impairment)}

The definition of default is harmonized with the definition of credit impairment.

The default of financial instruments pertaining to financial markets operations is a trigger for default of financial instruments of a corporate loan portfolio and vice versa. In practical terms it means that the assets of the $3^{\text {rd }}$ Stage are synchronized regardless of the type of business they pertain to.

Principles of Calculation of the expected credit losses value (ECL)

\section{Calculation of ECL of Stage 1 and 2}

The amount of ECL is defined by the following formula:

$$
\mathrm{ECL}=\sum_{t=1}^{T} \mathrm{MPD}_{\mathrm{t}} \cdot \mathrm{LGD} \cdot \mathrm{EAD}_{\mathrm{t}} \cdot \mathrm{D}_{\mathrm{t}} \cdot
$$

$\cdot \mathrm{MPD}_{\tau} \cdot \mathrm{LGD} \cdot \mathrm{EAD}_{\mathrm{T}+\tau} \cdot \mathrm{D}_{\mathrm{T}+\tau}$

where

MPD - marginal probability of default,

$\mathrm{MPD}_{\tau}-$ marginal probability of default of the last (incomplete) period,

LGD - loss given default (under contracts of non-default borrowers),

EAD - exposure at default,

$T$ - for Stage 2: the entier of the remaining life of the financial instrument (in years) since the reporting date; for Stage 1: $\mathrm{T}=1$, if the expected life of the financial instrument exceeds or equals 1 year, $\mathrm{T}=0$, if the expected life of the financial instrument is less than 1 year,

$\tau$ - for Stage 2: the fractional part of the remaining life of the financial instrument (in years) since the reporting date; for Stage 1: the expected life of the financial instrument (if it is less than 1 year), $\tau=0$, if the expected life of the financial instrument exceeds or equals 1 year

$D_{t}$ - discounting factor.

In case of a non-integral number of years of credit life MPD of the last period is calculated taking into consideration the adjusted conditional PD of the last period. See the formula for adjustment of the conditional PD below.

PDm $=1-(1-\text { PDy })^{\frac{m}{12}}$,

where

$\mathrm{PDm}$ - the conditional PD for the required period

PDy - one-year conditional PD of a full year

$\mathrm{m}$ - the required period (in months)
The cumulative PD is calculated as follows

$$
\mathrm{CPD}_{\mathrm{t}}=\left\{\begin{array}{c}
\mathrm{CPD}_{\mathrm{t}-1}+\left(1-\mathrm{CPD}_{\mathrm{t}-1}\right) \cdot \mathrm{PD}_{\mathrm{t}}, \mathrm{t}>0 \\
0, \mathrm{t}=0
\end{array}\right.
$$

The marginal PD is calculated as follows:

$$
\mathrm{MPD}_{\mathrm{t}}=\mathrm{PD}_{\mathrm{t}} \cdot\left(1-\mathrm{CPD}_{\mathrm{t}-1}\right)=\mathrm{CPD}_{\mathrm{t}}-\mathrm{CPD}_{\mathrm{t}-1} \text {. }
$$

\section{Calculation of ECL for Stage 3}

The value of ECL (except for the financial instruments for which an individual rate is calculated) is defined using the following formula:

$$
\mathrm{ECL}=\mathrm{LGD} \_ \text {def_t } \bullet \mathrm{EAD}_{\text {actual }} \text {, }
$$

where

$\mathrm{EAD}_{\text {actual }}$ - the actual value of credit requirement as of the date of calculation;

LGD_def_t - the expected level of losses in accordance with contracts of defaulted loaners. The expected level of losses (loss given default) is defined depending on the number of years which passed since the beginning of default.

$t$ - number of default years (rounded up to a whole number upwards)

\section{Discounting factor}

The discounting factor is calculated as follows:

$\mathrm{D}_{\mathrm{t}}=\frac{1}{(1+r)^{t-0,5}}$

where

$r$ - the original effective interest rate,

$\mathrm{t}$ - period (year) of calculation of ECL

If ECL is discounted for an incomplete period (see formula 2)

$$
D_{T+\tau}=\frac{1}{(1+r)^{\left(T+\frac{\tau}{2}\right)}},
$$

where

$r$ - the original effective interest rate,

$\mathrm{T}$ - the entire of the remaining life when calculating ECL

$\tau$ - the fractional part of the remaining life when calculating ECL

Adjustment of the period at discounting $(\mathrm{t}-0.5)$ means that discounting takes place as of the middle of the period (year). It is equivalent to the assumption that cash flows arrive evenly within the year and are not displaced to the beginning or end of the period.

\section{Taking into Consideration Forecasting Information and Number of Macroeconomic Scenarios}

In accordance with art. 5.5.17 (c) of IFRS 9 in order to assess ECL value it is necessary to use, among other 
things, the information on anticipated future economic conditions available as of the reporting date not entailing excessive cost or efforts. The approach applied to taking into consideration the anticipated information should take cognizance of the following principles:

- accord of the found statistical dependence with economic rationale;

- justification of applied assumptions;

- coherence (consistency) of the anticipated information;

- use of several external (for example, the forecast of the Ministry of Economic Development of the Russian Federation) and internal (the Bank forecast) data sources.

In accordance with IFRS 9 5.5.18 and B5.5.42 an organization should assess ECL on the basis of at least two scenarios [5]: "the probability of credit loss and the probability of absence of credit loss" the results of which have been weighted against the probability of occurrence of each of the scenarios.

The anticipated macroeconomic information may be included in the assessment at ECL level or at the level of individual components (PD, LGD, EAD).

When taking into consideration the macroeconomic information at the level of individual components the following approach is applied to adjustment:

- the values used to assess the probability of default for the whole life of the financial instrument: PDt, MPDt, CPD(t) (the frame within which taking into consideration of the anticipated information is applicable is defined depending on the forecast accuracy) (see Appendix 2) are adjusted;

- in case of materiality of influence of macroeconomic factors LGD is adjusted (materiality is evaluated by experts. The expert assessment may be based on the analysis carried out to find a dependence or on a consolidated opinion of experts involved in LGD modeling);

- in case of materiality of influence of macroeconomic factors EAD is adjusted (materiality is evaluated by experts. The expert assessment may be based on the analysis carried out to find a dependence or on a consolidated opinion of experts involved in EAD modeling).

\section{Concept of Calculation of Statistical Assessment of Credit Risk Components and ECL Value}

The model calibration as per IFRS 9 [5] is made in accordance with the principle of "PIT, at a point in time":
$\mathrm{PD}_{\mathrm{t}}^{\mathrm{PIT}}=\beta_{\mathrm{t}} \cdot \mathrm{PD}_{\mathrm{t}}^{\mathrm{TTC}}$,
where
$\mathrm{PD}_{\mathrm{t}}^{\text {PIT }}$ - the probability of default on the basis of PIT calibration;

$\mathrm{PD}_{\mathrm{t}}^{\mathrm{TTC}}$ - the probability of default on the basis of TTC calibration;

$\beta_{\mathrm{t}}$ - the scaling factor defined on the basis of data on the current degree of the portfolio default

The following methods are used to assess PD:

- use of external data on defaults;

- methods based on the migration matrix;

- methods based on approximation of historical default rates;

- the approach based on extrapolation by the exponential curve method (simplified approach).

The method based on use of external data on defaults evaluates PD on the basis of migration of ratings information on which is offered by external rating agencies (S\&P, Moody's, Fitch Ratings). If the Bank has no statistics to build a migration matrix using internal data the migration matrix built on the basis of external data is used. Depending on the purpose of modeling statistics of one or several rating agencies may be used. In case of inversions in the data of external matrices the matrix is adjusted (by experts or applying mathematical methods of function reduction to a monotone function).

$\mathrm{PD}$ assessment on the basis of migration matrices. The migration matrix is a square matrix which components contain the probability of change (probability of transfer) of the rating category of a corresponding Borrower.

$$
\mathrm{M}=\left[\begin{array}{ccc}
\mathrm{p}_{11} & \ldots & \mathrm{p}_{1, \mathrm{n}} \\
\ldots & \ldots & \ldots \\
\mathrm{p}_{\mathrm{n}-1,1} & \ldots & \mathrm{p}_{\mathrm{n}-1, \mathrm{n}} \\
0 & 0 & 1
\end{array}\right],
$$

where

$\mathrm{p}_{\mathrm{ij}}$ - probability of transfer to the rating category $\mathrm{j}$ in a certain time period provided it belongs to the rating category i.

In order to build the migration matrix the Bank uses a rating scale of internal credit ratings.

The Bank does not set the lower an upper limits of values for the default probability. In accordance with IFRS 9 the evaluation of default probability is unbiased. Consequently, the conservatism concept enshrined in the assessment model of default probability in accordance with IRB of Basel II cannot be used to calculate PD in accordance with IFRS 9 and when IRB of PD-models is brought into conformity with requirements of IFRS 9 such material adjustments are excluded (inter alia, the adjustment of "PD not less than $0.03 \%$ " established in accordance with Regulation 483-P is excluded) [6].

This is with the exception of the adjustment for the rating of the Russian Federation (the borrower's rating is not better than the rating of the Russian Federation): this adjustment remains unchanged.

Depending on availability of data when building the migration matrix consolidated (for example, consolida- 
tion of ratings 7-, 7, 7+ into one category) or initial rating categories may be used.

Estimation of probabilities of transfer is defined by the cohort analysis:

$\widehat{p_{i j}}=\frac{N_{i j}(t)}{N_{i}(t-1)}$,

where

$\mathrm{N}_{\mathrm{ij}}(\mathrm{t})$ - number of migrations from state I into state $\mathrm{j}$ within the period of $t$,

$\mathrm{N}_{\mathrm{i}}(\mathrm{t}-1)$ - number of transactions in the state of I within the period of $t-1$.

\section{Default probability over the horizon of 1 year}

One-year migration matrix $M_{0}$ is built on the basis of observations statistics for 12 calendar months. In order to take into consideration the most up-to-date information smaller periods may be used.

A medium one-year migration matrix is calculated by finding the arithmetic mean of one-year migration matrices obtained on a quarterly (monthly) basis.

The one-year probability of default $\left(\mathrm{PD}_{\mathrm{t}}\right)$ for each rating category is defined as the probability of transfer into the state of "10-default". In the migration matrix $\left(\mathrm{PD}_{t}\right)$ is stated in the last column of the yearly matrix of transfers. If the statistical frequency of defaults contravenes the probability of default in each rating grade of the Bank mater-scale scaling is performed. The adjustments are recorded in the Model Development Report.

\section{Probability of Default within the Life of a Financial Instrument}

When evaluating PD value on the basis of migration matrices the following principal assumptions are proposed:

future transfers into rating grades depend only on the current rating but not on previous ratings (Markov process feature);

probabilities of migration do not depend on a certain timepoint, i.e. the speeds of transfer do not change over time (homogeneity).

Formula to calculate the probability of default within the life of a financial instrument:

$$
\mathrm{M}_{\mathrm{T}}=\mathrm{M}_{1}^{\mathrm{T}} \text {, }
$$

where $\mathrm{T}$ - life of the financial instrument

The column in the multiyear matrix which shows the probability of transfer in the state of default is the cumulative probability of default in a corresponding period (cPD). Use of the migration matrix helps to take into account the full information on migration of ratings when calculating the probability of default for the whole life.

Assessment of the survival function parameters

Profiles of cumulative PDs are built by evaluation of distribution parameters of cumulative DR.

\section{On the basis of Weilbull distribution [7]:}

Parameters of Weilbull distribution $\mathrm{k}$ and $\lambda$ are evaluated on the basis of a linear regression of the double logarithm of the survival function. The survivorship function is defined by the following formula:

$\mathrm{S}(\mathrm{t}):=1-\mathrm{F}(\mathrm{t} ; \mathrm{k}, \lambda)$,

where $\mathrm{F}(\mathrm{t} ; \kappa, \lambda)$ - a two-parameter Weibull distribution function.

$\mathrm{F}(\mathrm{t} ; \kappa, \lambda)=\operatorname{cDR}(\mathrm{t} ; \kappa, \lambda)=\left\{\begin{array}{c}1-\mathrm{e}^{-\left(\frac{\mathrm{t}}{\lambda}\right)^{\mathrm{k}}}, \mathrm{t}>0 \\ 0, \mathrm{t} \leq 0\end{array}\right.$,

where $\mathrm{k}>0$ defines the shape of the distribution function. $\mathrm{k}<1$ indicates recession of default in course of time, $\mathrm{k}=1$ indicates stability of default over time, $\mathrm{k}>1$ indicates increase of default in course of time;

$\lambda>0$ - scale parameter, regulates the survival time.

\section{On the basis of Weilbull modified distribution:}

Cumulative PD are modeled by choosing the distribution parameters which describe the behaviour of cumulative default rates most accurately. The two-parameter Weibull modified distribution function is presented as follows:

$\mathrm{F}(\mathrm{t}, \alpha, \beta)=\operatorname{cDR}(\mathrm{t}, \alpha, \beta)= \begin{cases}\frac{1-\mathrm{e}^{-\left(\mathrm{e}^{-\left(\alpha \cdot \mathrm{t}^{\beta}\right)}\right)}}{\left(1-\mathrm{e}^{-1}\right)}, \mathrm{t}>0, \\ 0 \quad, \mathrm{t} \leq 0\end{cases}$

where

$\alpha$ and $\beta<0$-parameters of Weibull modified distribution, $\operatorname{cDR}(\mathrm{t}, \alpha, \beta)$ - cumulative default rate in the $\mathrm{t}$ year. Simplified approach: PD assessment on the basis of extrapolation by the exponential curve method

This approach suggests convergence of conditioned TTC of PD profiles in a certain year of life in the central tendency point. Evaluation of multiyear PD on the basis of the Simplified Approach consists in modeling of conditioned PD for the whole life and is based on an expert or empiric assessment of two parameters:

- convergence point of PD profiles;

- convergence speed of PD profiles.

The principal stages of obtaining marginal PIT of multiyear PD are presented below:

- defining the parameters: convergence point and convergence speed;

- building of multiyear conditioned TTC of PD profiles on the basis of parameters and TTC of PD for 12 months;

- PIT calibration of conditioned TTC of PD profiles for the first two years of life; 
- obtaining of multiyear marginal and cumulative PIT of PD profiles by means of ECL conditioned for calculation and assignment to the credit risk stages.

Figure 1 shows the approach which describes parameters for building of conditioned PD profiles.

CT is defined as medium empirical default rate, the convergence speed is defined by experts and depends on the average life of a loan and modeling level.

When applying the approach to PD assessment on the basis of extrapolation by the exponential curve method it is possible, for example, to use the following formula (other ways to describe exponential curves of conditioned PD levels are possible):

$$
\mathrm{PD}(\mathrm{t})=\exp \left(\ln \left(\mathrm{PD}(\mathrm{t}-1)\left(1-\frac{\mathrm{t}-1}{\mathrm{~T}}\right)+\ln (\mathrm{CT}) \frac{\mathrm{t}-1}{\mathrm{~T}}\right)\right.
$$

where

CT - central tendency,

$\mathrm{T}$ - convergence time,

$\mathrm{t}$ - assessment period, in years, $\mathrm{t}>1$.

An example of PD calculation in accordance with the simplified approach is introduced in Appendix 4.

Figure 1. Conditioned PD profiles on the basis of the simplified (parameter-oriented) approach

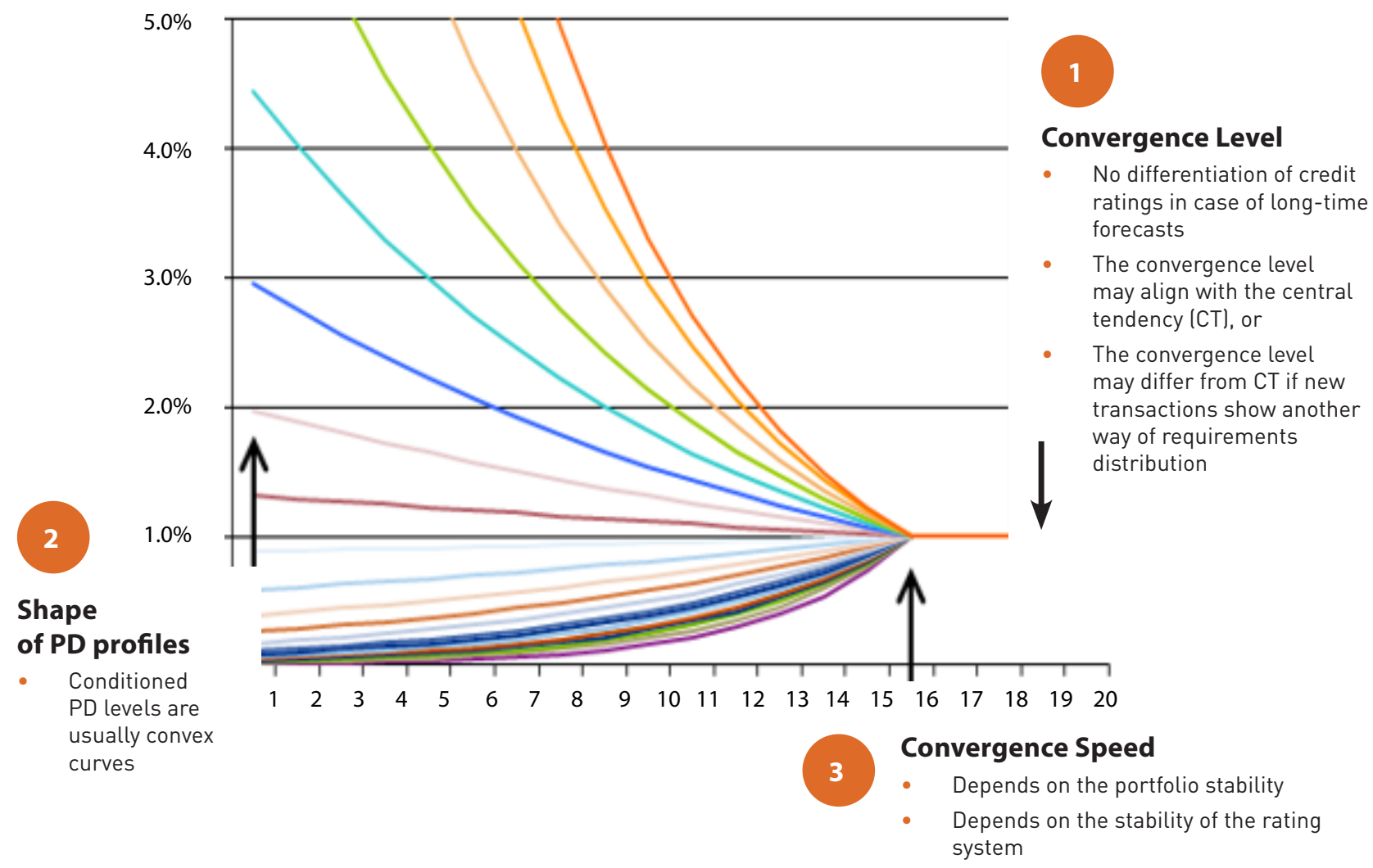

\section{Conclusion}

Implementation of IFRS 9 requires change of traditional banking approaches and improvement of the existing methodologies and models of credit risk assessment including the cases of calculation of expected credit losses. In accordance with IFRS 9 there exist three approaches to ECL assessment:

The principal approach based on three stages of credit risk:

The simplified approach - the reserve is assessed in the amount of ECL for the whole life of an asset or in accordance with another approach.
Approach for POCI - at first recognition the reserve is not created, an asset is carried at adjusted value after deduction of the impairment effect; the interest return is calculated on the basis of the adjusted effective rate of the amortized cost; subsequent assessment of the reserve amounts to the change of ECL for the whole life.

The date of first recognition is usually understood as the date of signing the contract.

The present research has developed methodological principles and offered solutions applicable in bank practices (introduced criteria of defining transfer of assets from stage to stage, evaluated PD on the basis of extrapolation by the exponential curve method as per the simplified approach). 
We also conducted a comparative assessment of various models of PD lifetime assessment (Appendix 4).

- Weilbull distribution: may be applied instead of migration matrices if corrections in the master scale are not necessary and use of the generator matrix decreases the number of corrections introduced in an expert way/manually

- Migration matrices: applied if data on defaults is insufficient (for applying Weilbull distribution)

- Generator matrix: may be used instead of migration matrices if corrections in the master scale are not necessary and use of the generator matrix decreases the number of corrections introduced in an expert way/manually.

\section{References}

1. International Accounting Standard (IAS) 39. Financial Instruments: Recognition and Measurement. 2016. URL: http://www.consultant.ru/ document/cons_doc_LAW_193673/(In Russ.).

2. Vasileva A.F., Zhevaga A.A., Morgunov A.V. Methods of managing credit risk of corporate clients in the face of variability of requirements of financial reporting standards. Upravlenie finansovymi riskami. 2017;(4):258-268. (In Russ.).

3. International Financial Reporting Standard (IFRS) 9. Financial Instruments. 2018. URL: http://www. consultant.ru/document/cons_doc_LAW_201982/ (In Russ.).

4. An introduction to reliability and life distributions objectives. Coventry: University of Warwick; 2018.

5. Guidance on credit risk and accounting for expected credit losses (BCBS 350). 2015. URL: https://www.bis. org/bcbs/publ/d350.pdf

6. Bank of Russia Regulation No. 483-P "On the procedure for calculating credit risk amount based on internal ratings". 2015. URL: http://www.consultant. ru/document/cons_doc_LAW_186639/ (In Russ.).

7. Dodson B. The Weibull analysis handbook. Milwaukee, WI: ACQ Quality Press; 2006.

8. Kuznetsova Yu.I., Zhuravlev I.B. Application of the Bayesian estimate of the probability of a rare event to determining the probability of default of a counterparty. Upravlenie finansovymi riskami. 2013;(2):94-102. (In Russ.).

9. Svetlov K.K. Stochastic market analysis methods. Cand. econ. sci. diss. Synopsis. St. Petersburg: St. Petersburg State University; 2015. 24 p. URL: https:// disser.spbu.ru/disser2/752/aftoreferat/Svetlov_ Avtoreferat.pdf (In Russ.). 


\section{Appendix 1: PIT-calibration}

One of the principal requirements of the new Standard is evaluation of ECL at a point in time (PIT) [1] which implies use of historic record, information available for the time being, as well as forecasting information (macroeconomic factors). TTC of PD represents an average PD over the whole economic cycle, the assessment of this PD is based on all available information about the borrower. TTC of PD is stable in time and has no correlation with the economic cycle.

PIT calibration may be obtained from the traditional long-term cyclic assessment (TTC) as shown in the figure below.

PIT calibration should comprise macroeconomic information.
PIT calibration is conducted applying one of the four methods described below.

\section{Linear scaling}

The method is based on the ratio of the portfolio default rate and portfolio $\mathrm{PD}$ :

$\mathrm{PD}_{\mathrm{t}}^{\mathrm{PIT}}=\beta_{\mathrm{t}}^{\mathrm{PIT}} \cdot \mathrm{PD}_{\mathrm{i}, \mathrm{t}},(17)$

where $\beta_{\mathrm{t}}^{\mathrm{PIT}}=\frac{\mathrm{DR}_{\mathrm{t}}}{\text { Portfolio_PD }}$

The main restriction of this approach is unlimitedness of the line function due to which PD may go beyond the limits [0:100\%].

\section{Bayesian approach [8]}

PIT calibration is conducted on the basis of Bayesian formula where PD of a contract/client/risk of a category is scaled in accordance with default rate and portfolio PD.

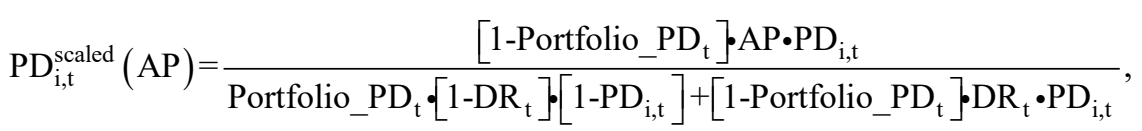

where Portfolio_PD - TTC of portfolio PD as of the reporting date $t$,

$\mathrm{PD}_{\mathrm{i}, \mathrm{t}}-\mathrm{PD}$ for 12 months of risk category $\mathrm{i}$,

AP - anchor point.

\section{Anchor point approach}

PIT calibration is conducted on the basis of the current default rate of the portfolio using the following formula:

$$
\mathrm{PD}_{\mathrm{i}, \mathrm{t}}^{\text {scaled }}=\frac{1}{1+\mathrm{e}^{-\left(\mu+\beta \cdot \text { Score }_{\mathrm{j}}\right)}},
$$

where parameters $\mu$ and $\beta$ are calculated as follows:

- the average PD value for the clients from the selection used for the calibration is equated with the central tendency value.

- the parameters are calculated by minimizing the difference between the anchor point $(A P)$ and the average model value of PD in the whole selection.

\section{Vasicek formula [9]}

In order to scale TTC of PD in PIT of PD function Z is used which predicts the default rate.

$\mathrm{PD}_{\mathrm{t}, \mathrm{i}}^{\mathrm{PIT}}=\mathrm{N}\left(\frac{\mathrm{N}^{-1}\left(\mathrm{PD}_{\mathrm{t}, \mathrm{i}}^{\mathrm{TTC}}\right)-\sqrt{\rho} \mathrm{Z}}{\sqrt{1-\rho}}\right)$

where

$\mathrm{N}()$ - standard normal distribution,

$\mathrm{N}^{-1}()$ - inverse normal distribution,

$\rho$ - parameter of influence of a macroeconomic factor calculated by the least square method using the reduced gradient algorithm,

$\mathrm{PD}_{\mathrm{t}, \mathrm{i}}^{\mathrm{PIT}}$ - PD calibrated at a point in time,

$\mathrm{PD}_{\mathrm{t}, \mathrm{i}}^{\mathrm{TTC}}$ - PD calibrated "with reference to cycle",

$\mathrm{Z}$ - standardized function of a macroeconomic factor/ factors.

Figure 2. PIT calibration process

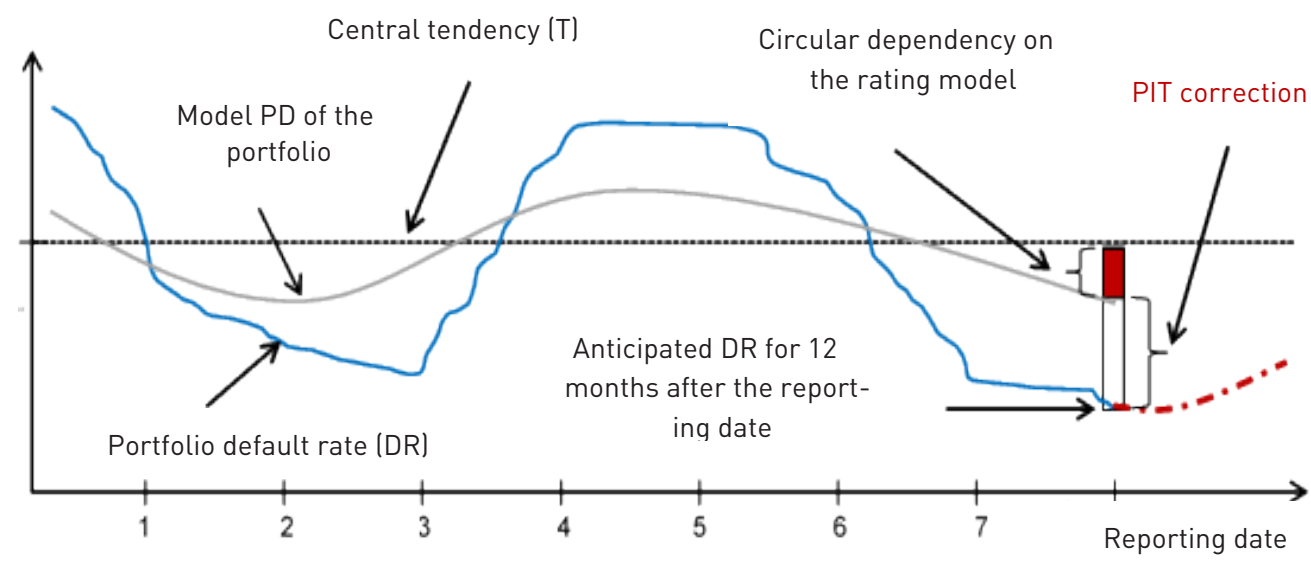




\section{Appendix 2: Defining the impairment stage}

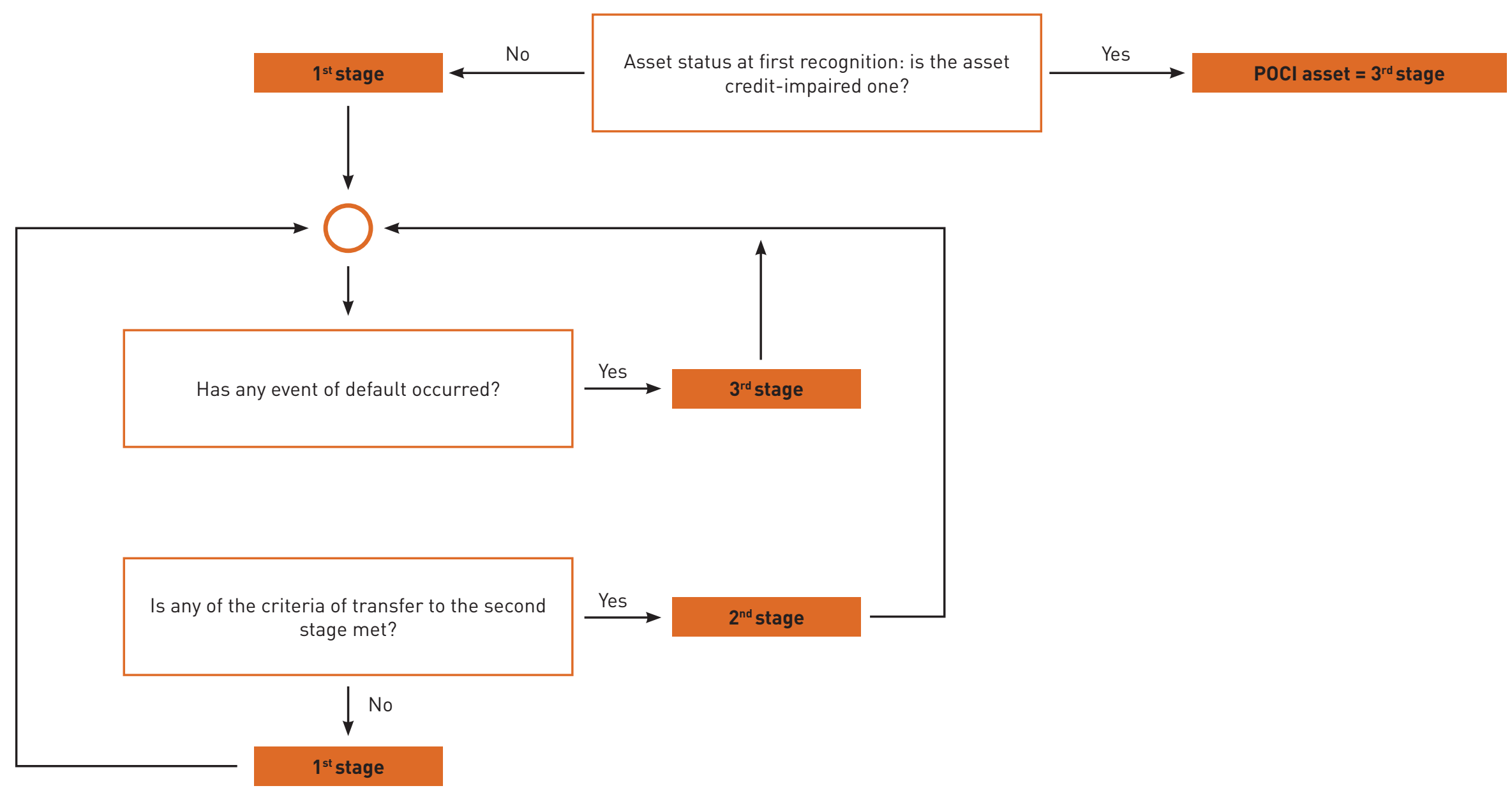




\section{Appendix 3: Justification of the chosen pd modeling approaches}

\begin{tabular}{|c|c|c|c|}
\hline Method & Advantages & Drawbacks & When to be applied? \\
\hline $\begin{array}{l}\text { Weilbull } \\
\text { distribution }\end{array}$ & $\begin{array}{l}\text { The model approximates model DR much better to the } \\
\text { observed DR that migration matrices do it } \\
\text { Simplicity of use }\end{array}$ & $\begin{array}{l}\text { Requires a lot of data on } \\
\text { defaults }\end{array}$ & $\begin{array}{l}\text { Applied in case of a large amount of data on defaults (for DR building } \\
\text { for several years) }\end{array}$ \\
\hline $\begin{array}{l}\text { Migration } \\
\text { matrices }\end{array}$ & $\begin{array}{l}\text { Uses more intensively the existing information on the } \\
\text { segment and for this reason may be built with a smaller } \\
\text { number of defaults } \\
\text { Existence of a convenient mathematical apparatus } \\
\text { Possibility of introducing adjustments (for example, at } \\
\text { master scale) }\end{array}$ & $\begin{array}{l}\text { at long time intervals (more } \\
\text { than } 9 \text { years) it exaggerates } \\
\text { the result significantly - may } \\
\text { be disregarded on account of } \\
\text { discounting }\end{array}$ & $\begin{array}{l}\text { Applied in case of insufficient data on defaults (for use of Weilbull distri- } \\
\text { bution) }\end{array}$ \\
\hline
\end{tabular}

Uses more intensively the existing information on the segment and for this reason may be built with a smaller number of defaults

Existence of a convenient mathematical apparatus

Generator Existence of convenient mathematical methods of intro-

matrix ducing adjustments

Possibility to get assessments of PD for nondiscrete time intervals

Possibility to get nonzero PD with high ratings even in case of absence of observed defaults
High complexity of use

Absence of an intuitive explanation when introducing corrections in the master scale

At long time intervals (more than 9 years) it exaggerates

the result significantly - may

be disregarded on account of

discounting
May be applied instead of migration matrices, if:

Corrections at master scale are not required and

Application of the generator matrix decreases the number of corrections introduced in the expert way/manually 


\section{Appendix 4: Example of calculation of PD in accordance with the simplified approach to PD calculation}

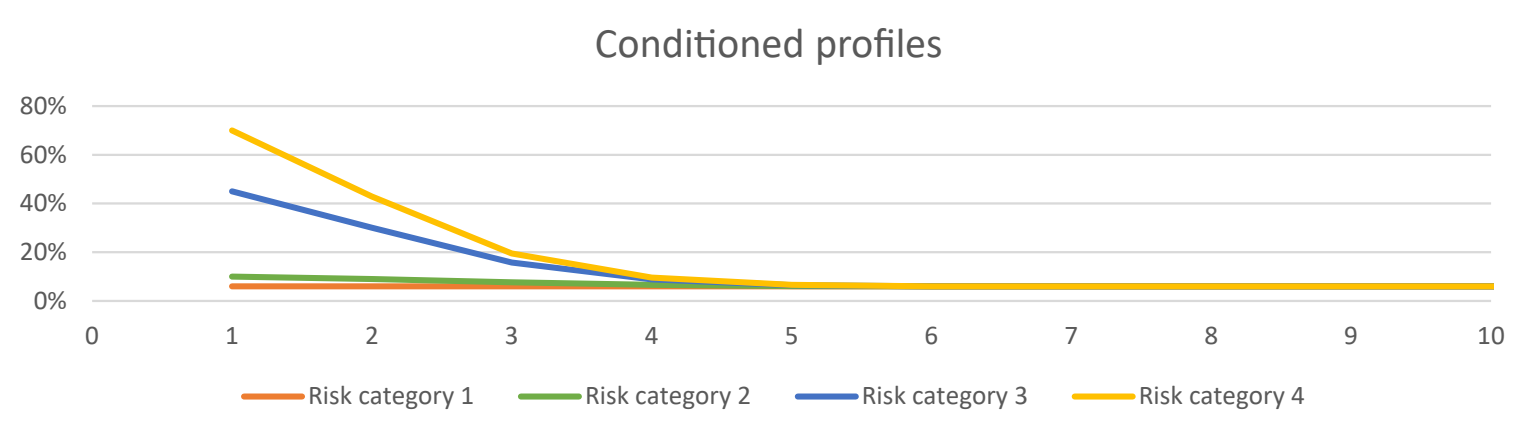

Cumulative profiles

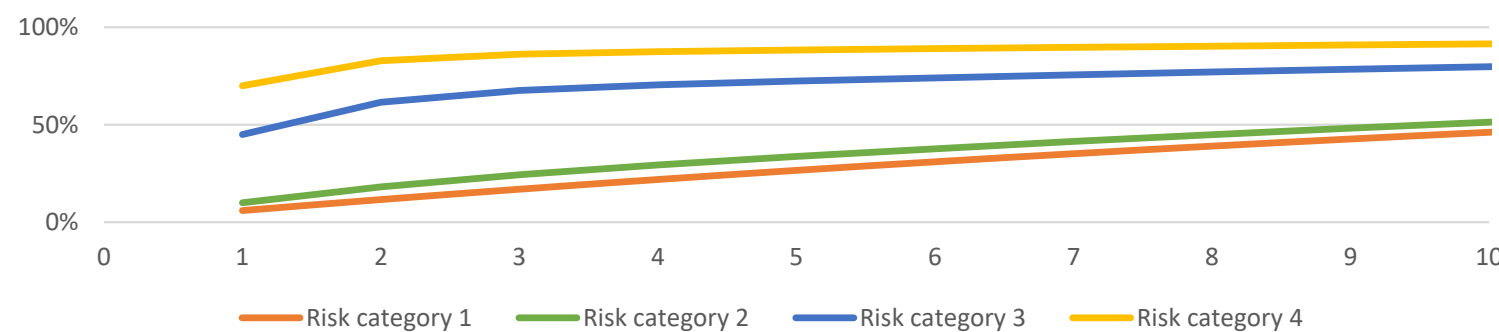

Marginal profiles

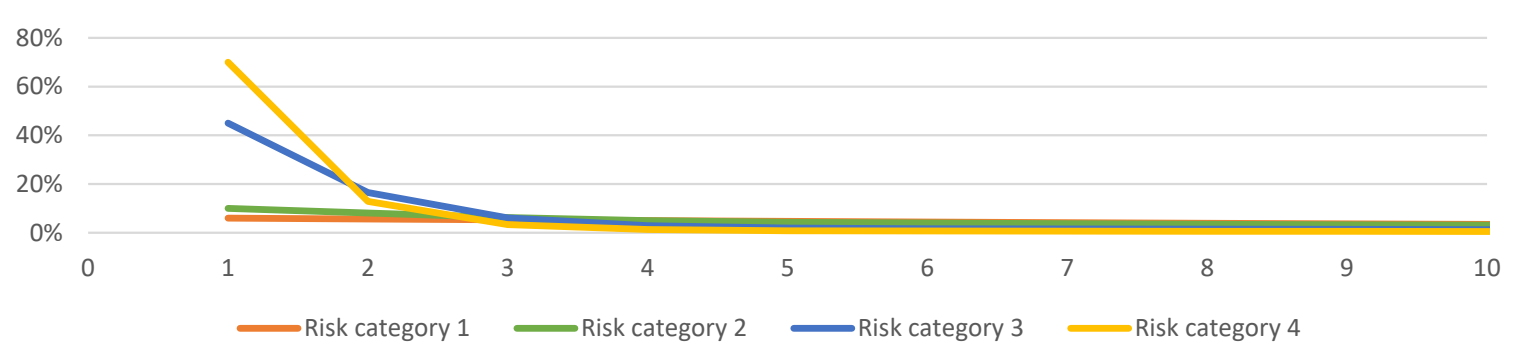

